09

\title{
Анизотропия оптических свойств пленок гексагонального нитрида бора
}

\author{
() Л.В. Котова ${ }^{1}$, Л.А. Алтынбаев ${ }^{1}$, М.О. Жукова ${ }^{2}$, В.Т. Hogan $^{3,4}$, А. Балдычева ${ }^{3}$, \\ Д.М. Курбатов ${ }^{1}$, В.П. Кочерешко ${ }^{1}$ \\ ${ }^{1}$ Физико-технический институт им. А.Ф. Иоффре РАН, \\ Санкт Петербург, Россия \\ ${ }^{2}$ Университет ИТМО, \\ Санкт Петербург,Россия \\ ${ }^{3}$ Department of Engineering, University of Exeter, \\ Exeter EX4 4QF, UK \\ ${ }^{4}$ OPEM, ITEE, University of Oulu, \\ 90014 Oulu, Finland \\ E-mail: kotova@mail.ioffe.ru
}

Поступила в Редакцию 15 апреля 2021 г.

В окончательной редакции 15 апреля 2021 г.

Принята к публикации 18 апреля 2021 г.

Тонкие пленки гексагонального нитрида бора толщиной несколько моноатомных слоев были изготовлены путем расщепления объемных образцов в ультразвуковой ванне. Исследовались спектры пропускания, отражения и фотолюминесценции таких пленок. Были измерены спектральные зависимости линейной и круговой поляризации прошедшего через образец света. Исследование с помощью сканирующей электронной микроскопии показало однородность полученных образцов. Однако исследование параметров Стокса прошедшего через образец света позволило установить наличие скрытой анизотропии оптических свойств этих пленок.

Ключевые слова: нитрид бора, оптическая анизотропия, спектроскопия, поляризация, тонкие пленки.

DOI: 10.21883/FTT.2021.09.51315.087

\section{1. Введение}

В последние годы особый интерес исследователей привлекают двумерные атомарно тонкие материалы. С данными системами связывают, в частности, перспективы создания ван-дер-ваальсовых гетероструктур, в которых двумерные слои разных полупроводников располагаются один за другим. Такие структуры, благодаря сильной ковалентной связи внутри слоев и относительно слабой связи между слоями, сохраняют многие свойства исходных материалов. При создании гетероструктур, благодаря слабой ван-дер-ваальсовой связи между слоями, не нужно заботиться о согласовании параметров решетки, что позволяет использовать весь спектр двумерных материалов, невзирая на величину постоянной решетки.

Наиболее ярким представителем двумерных полупроводников является графен, монослой атомов углерода, расположенных в узлах двумерной гексагональной решетки. Графен является полуметаллом с нулевой шириной запрещенной зоны. Другие соединения имеют ширину запрещенной зоны от нуля до $6 \mathrm{eV}$, что позволяет получать гетероструктуры с очень широким спектром свойств.

Интерес к тонким слоям гексагонального нитрида бора обусловлен стабильностью соединения в двумерной форме и графеноподобной структурой. Поэтому нитрид бора является одним из самых подходящих материалов для барьерных слоев гетероструктур, с большими перспективами применения в наноэлектронике [1] и оптоэлектронике [2].

Самой простой и распространенной технологией получения тонких, вплоть до моноатомных, слоев таких материалов является механическое отщепление слоев с помощью липкой ленты. Однако такой способ изготовления наноструктур трудно назвать прогрессивным. Для усовершенствования технологии изготовления тонких слоев графеноподобных материалов разрабатываются разные способы. Одной из перспективных технологий является отщепление тонких слоев слоистых полупроводников с помощью ультразвука в ванне с жидкостью. Однако такая технология также не лишена недостатков, так как в результате получаются пленки со случайным распределением микрокристаллов по размерам и положению.

В настоящей работе описано изготовление тонких пленок гексагонального нитрида бора путем расщепления объемного нитрида бора с помощью ультразвука и экспериментальное исследование их оптических свойств. В частности, исследовались спектры фотолюминесценции при фотовозбуждении лазерами с различными длинами волн, спектры пропускания и отражения, а также спектральные зависимости параметров Стокса прошедшего через образец света с линейной и круговой поляризацией при нормальном падении. 

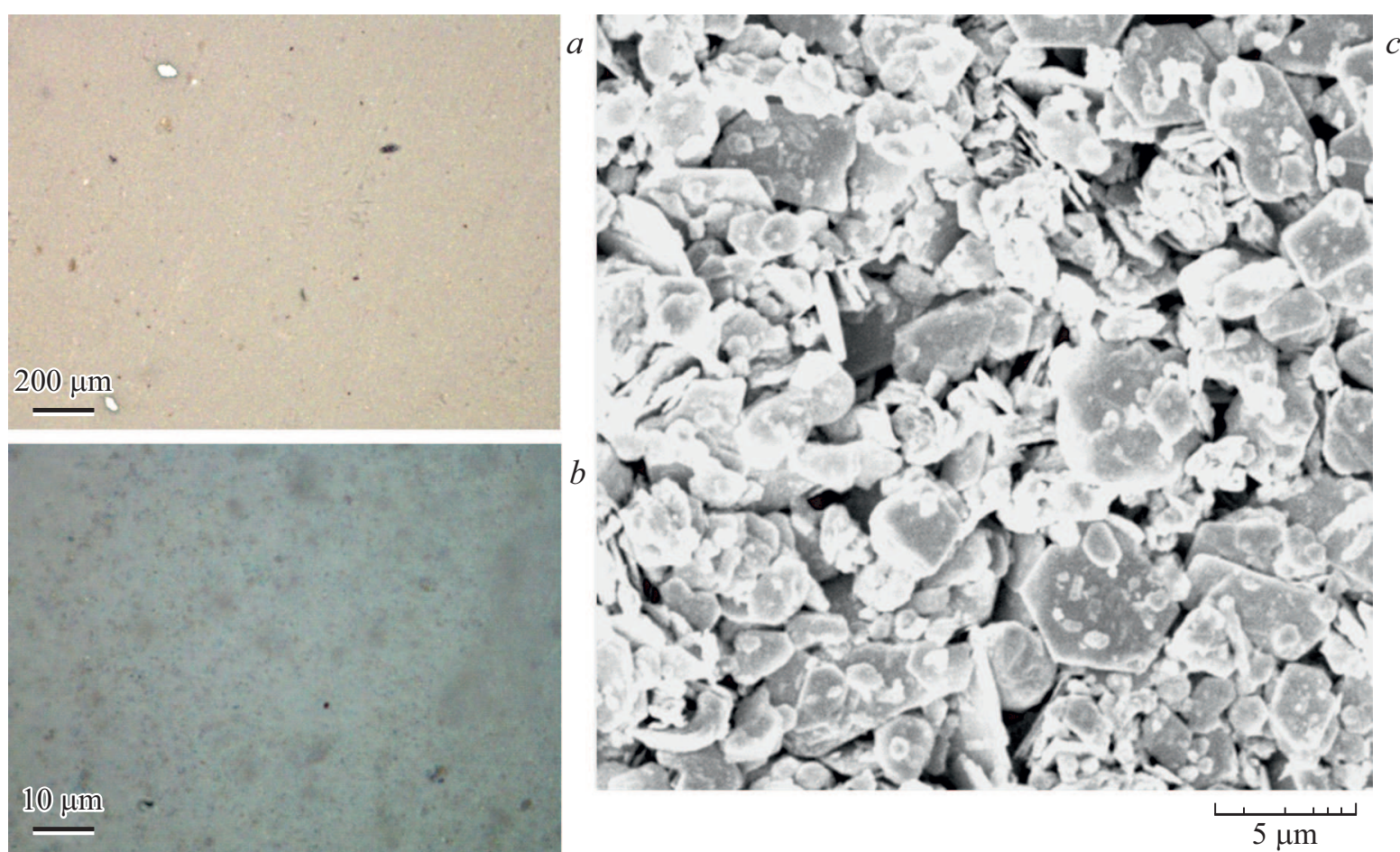

Рис. 1. Изображения поверхности образца при различном увеличении: $a$ и $b-$ полученные с помощью оптического микроскопа в немонохроматическом свете, $c$ - полученное с помощью сканирующего электронного микроскопа.

\section{2. Эксперимент}

Тонкие пленки гексагонального нитрида бора $(h$-BN) получали на подложке из полиэтилентерефталата следующим способом. Порошок объемного $h$-BN первоначально диспергировали в смеси изопропанола и деионизированной воды в соотношении $60: 40$. После энергичного встряхивания для максимальной дезагрегации и диспергирования частиц $h$-BN раствор затем подвергали ультразвуковой обработке в ультразвуковой ванне (James Products $120 \mathrm{~W}$ High Power $2790 \mathrm{ml}$ Ultrasonic Cleaner), заполненной деионизированной водой. Для обеспечения достаточного расслаивания образца использовали пять периодов продолжительностью в $30 \mathrm{~min}$ каждый, чтобы предотвратить чрезмерный нагрев растворителя. Затем полученные дисперсии подвергали центрифугированию в течение $10 \mathrm{~min}$ при скорости $2000 \mathrm{rpm}$ для раздробления остаточного объемного материала и сужения распределения размеров частиц, присутствующих в дисперсии. После центрифугирования дисперсию разделяли на фракции, при этом экстрагировали только неосажденную фракцию, чтобы гарантировать, что остались только частицы подходящего размера. Затем полученную дисперсию сушили в вакууме (при давлении $\sim 0.1 \mathrm{~atm}$ ) на линии Шленка для полного удаления растворителя. Полученный порошок массой $606 \mathrm{mg}$ затем повторно диспергировали в $12 \mathrm{ml}$ изопропанола, смешанного с $8 \mathrm{ml}$ деионизированной воды, с получением концентрации около $30 \mathrm{mg} / \mathrm{ml}$. Этот повторно диспергированный раствор обрабатывали ультразвуком в течение дополнительных $30 \mathrm{~min}$ для обеспечения однородной дисперсии.

Для получения однородных тонких пленок из уложенных друг на друга слоев многослойного $h$-BN повторно диспергированный раствор фильтровали через микропористую (с размером пор $0.2 \mu \mathrm{m}$ ) политетрафторэтиленовую мембрану. Такие пленки широко исследовались для различных двумерных материалов, и было показано, что дисперсии оксида графена и дисульфида молибдена дают высококачественные пленки [3-7]. Перенос или осаждение тонких пленок, полученных в результате фильтрации дисперсии, производили описанным ранее способом [8-10]. Широкое использование данной технологии указывает на простоту и масштабируемость метода расширенной интеграции двумерного материала. Мембрану переносили на желаемую подложку, при этом отфильтрованный 2D-материал контактировал с подложкой. Для смачивания мембраны использовался изопропанол. Затем субстрат нагревался до $70^{\circ} \mathrm{C}$, изопропанол выпаривался, высвобождая $h$-BN из мембраны. Этот процесс совместим со многими различными подложками. Полученные таким образом тонкие пленки размером $\sim 1.0 \times 1.0 \mathrm{~cm}$ были успешно перенесены на подложку для дальнейших измерений.

Изображения поверхности полученных образцов при различном увеличении представлены на рис. 1, $a-c$. Эти изображения показывают, что данный образец представляет собой „слипшийся порошок“, состоящий из тонких кристаллических пластинок BN с поперечным размером от 5 микрон и меньше и толщиной от десяти моноатом- 
ных слоев до одного. Визуально эти микрокристаллики ориентированы полностью хаотично. Поверхность образца не имеет никаких выделенных направлений как на масштабе в сотни микрон, так и на масштабе единиц микрон.

Мы исследовали спектры фотолюминесценции, отражения и пропускания поляризованного света этих образцов при комнатной температуре. Спектры были получены на установке, состоящей из спектрометра с фокусным расстоянием $0.5 \mathrm{~m}$, оснащенного CCD-камерой. Для возбуждения фотолюминесценции использовались лазеры с длинами волн излучения $\lambda=244 \mathrm{~nm}$ $(5.08 \mathrm{eV}), \lambda=532 \mathrm{~nm}(2.33 \mathrm{eV})$ и $\lambda=662 \mathrm{~nm}(1.87 \mathrm{eV})$. При регистрации спектров пропускания и отражения использовалась галогенная лампа.

Для подтверждения кристаллической структуры образца был снят спектр комбинационного рассеяния света. Спектр показал наличие кристаллической структуры, соответствующей структуре кристаллов гексагонального нитрида бора. При этом наблюдался довольно интенсивный рассеянный фон, свидетельствующий о большом числе дефектов.

В спектрах фотолюминесценции (ФЛ) при возбуждении с длиной волны $224 \mathrm{~nm}$, выше непрямого края запрещенной зоны, наблюдалась широкая полоса ФЛ, шириной порядка $1 \mathrm{eV}$, с максимумом при энергии $3.6 \mathrm{eV}$. При возбуждении излучением с энергией ниже края фундаментального поглощения идеального кристалла $h$-BN также наблюдался набор узких линий в области энергий $\sim 1.5 \mathrm{eV}$.

Наличие полос излучения в глубине запрещенной зоны указывает на то, что они могут быть связаны с глубокими примесями, а также с центрами окраски. Зависимость спектра фотолюминесценции от энергии возбуждающего света указывает на то, что наряду с переходами зона-вакансия наблюдаются и внутрицентровые переходы. Расчеты показывают, что положение максимумов фотолюминесценции тонких пленок коррелирует с энергиями переходов на энергетические уровни центров окраски $[11,12]$.

На рис. $1, a$ и $b$ видно, что поверхность образца матовая. При этом зеркальное отражение от поверхности практически отсутствует, и наблюдается сильное рэлеевское рассеяние света.

Мы измерили спектры рэлеевского рассеяния в зависимости от угла падения света на образец (угол $\Phi$ на рис. 2) в интервале углов от нуля до $45^{\circ}$ и от азимутального угла между плоскостью падения и краем образца (угол $\Theta$ на рис. 2) в интервале от 0 до $360^{\circ}$. Спектры не имели никакой структуры, кроме одного широкого максимума шириной $1 \mathrm{eV}$ при энергии $1.7 \mathrm{eV}$. Было обнаружено, что интенсивность рассеянного света не зависит от азимутального угла $\Theta$. При изменении угла падения $\Phi$ не обнаружилось каких-либо качественных различий между спектрами, кроме изменения их общей интенсивности.

В спектрах пропускания наблюдалось сильное поглощение в области внутри запрещенной зоны $h$-BN, уже на

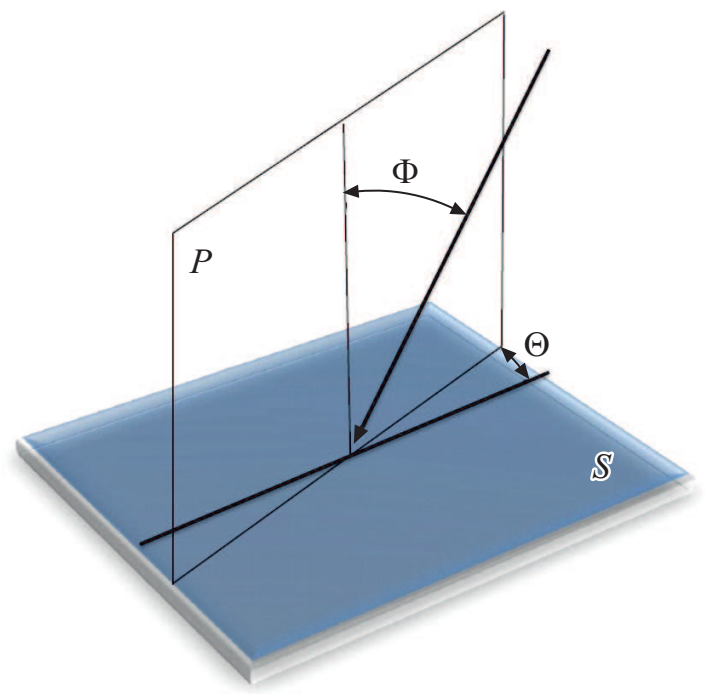

Рис. 2. Схема эксперимента: $P-$ плоскость падения, $S-$ поверхность образца, $\Phi-$ угол падения, $\Theta-$ азимутальный угол между плоскостью падения и краем образца.

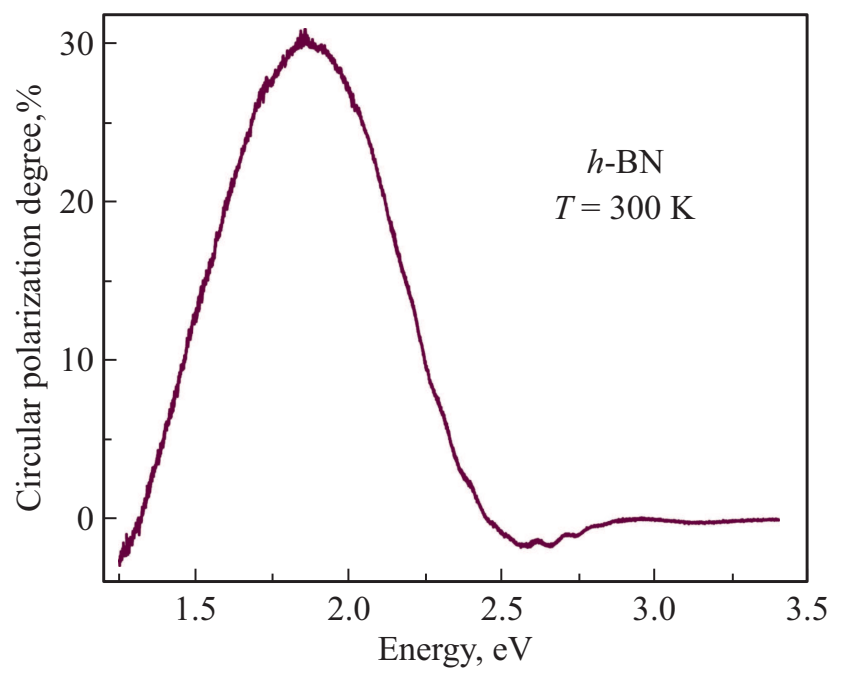

Рис. 3. Спектральная зависимость степени круговой поляризации пропускания образца $h$-BN.

энергиях выше $3 \mathrm{eV}$, со слабо выраженной структурой. В области прозрачности от 1.3 до $3.0 \mathrm{eV}$ в спектрах пропускания не наблюдалось никаких интерференционных особенностей, что говорит о том, что толщина образца заметно меняется на масштабах порядка размера светового пучка $(\sim 1 \mathrm{~mm})$.

Мы провели измерения спектров пропускания поляризованного света в области прозрачности образца и измерили параметры Стокса прошедшего через образец света. Были измерены: степень круговой поляризации (рис. 3), степень линейной поляризации (рис. 4,a) и степень линейной поляризации в осях, повернутых на $45^{\circ}$ (рис. $\left.4, b\right)$. 

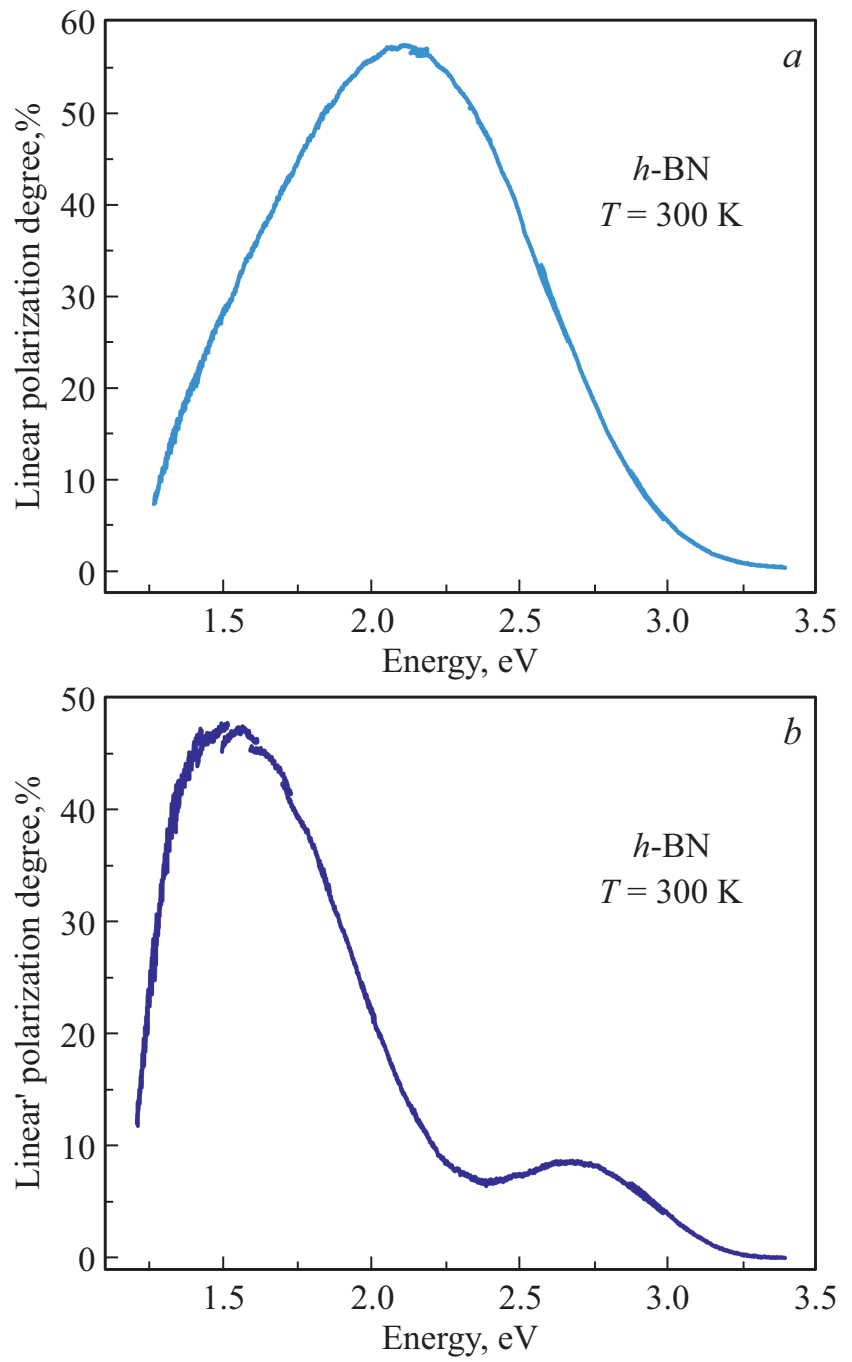

Рис. 4. Спектральная зависимость степени линейной поляризации пропускания $h$-BN: $a-$ в осях $(x, y)$, поляризация падающего света направлена вдоль оси $x ; b-$ в осях $\left(x^{\prime}, y^{\prime}\right)$, повернутых на $45^{\circ}$ относительно осей $(x, y)$; ось $z$ направлена по нормали к поверхности образца.

Из полученных данных однозначно следует вывод, что во всем измеренном спектральном интервале наблюдается явление двулучепреломления света. Это явление проявляется в конверсии линейной поляризации в эллиптическую. На длине волны $550 \mathrm{~nm}$ степень круговой поляризации меняла знак. Это изотропная точка в спектре, в которой меняется знак двулучепреломления. В то же время этот эффект достигает максимума на длине волны $\lambda \sim 650 \mathrm{~nm}$.

Спектральные зависимости степени линейной поляризации подтверждают вывод о наличии двулучепреломления и позволяют определить направление оптических осей.

Были проведены измерения явления двулучепреломления в зависимости от точки на образце. Оказалось, что по всей площади образца $\left(\sim 1 \mathrm{~cm}^{2}\right)$ направление оптической оси не меняется.

\section{3. Обсуждение результатов}

Очевидно, что двулучепреломление вызвано наличием выделенной оптической оси в исследуемом образце. Появление оптической оси в порошке может быть обусловлено как анизотропией самих частиц порошка, так и анизотропией их расположения [13]. Однако анизотропия только самих частиц порошка не может привести к анизотропии всего образца, но, конечно, может привести к локальной анизотропии.

Отдельные гексагональные кристаллы нитрида бора действительно анизотропны. Показатели преломления света вдоль гексагональной оси и перпендикулярно ей сильно отличаются [14]. В порошке BN ориентация кристалликов, как видно из рис. $1, c$, совершенно хаотична (по крайней мере, на масштабах от 200 до 1 микрона). Таким образом, двулучепреломление не может быть вызвано анизотропией самих микрокристаллов BN.

Однако поляризационные измерения однозначно указывают на наличие такой анизотропии. Более того, установлено, что направление оптической оси одно и то же по всей площади образца. Это указывает на то, что причина анизотропии не скрывается в свойствах отдельных кристалликах, а является общей для всего образца, причем проявляется на больших (сантиметровых) расстояниях. Было проверено, что сама подложка оптически изотропна. Изменения отраженного/рассеянного от образца света показали, что в отличие от случая, описанного в работе [15], наклон микрокристаллов в порошке также хаотичен.

Наличие скрытого порядка в неупорядоченном порошке может говорить о том, что мы имеем дело с конечной системой микрокристаллов, в которой нет полного усреднения свойств. Похожий случай, когда видимая „на глаз“ анизотропия отсутствовала, но имело место анизотропное рассеяние света, теоретически моделировалась в статье [13].

Для описания наблюдаемого явления можно попытаться воспользоваться моделью эффективной среды [16]. Несмотря на то, что размеры частиц в нашем случае больше длины волны света и применимость этой модели не вполне обоснована, основные свойства среды должны описываться (по крайней мере, качественно) и в этой модели. Воспользуемся моделью МаксвеллаГарнетта. Диэлектрическую проницаемость эффективной среды $\varepsilon_{e f f}$, состоящей из нескольких компонентов, можно найти как решение уравнения

$$
\sum_{i=1}^{N} f_{i} \theta_{i}\left(\varepsilon_{e f f}-\varepsilon_{i}\right)=0 .
$$

Здесь $\varepsilon_{i}$ - диэлектрические проницаемости компонентов среды, $f_{i}$ - фактор заполнения компонента $i$, $\theta_{i}-$ формфактор компонента $i$. При этом должно 
выполняться условие нормировки

$$
\sum_{i=1}^{N} f_{i}=1, \quad \sum_{i=1}^{N} \theta_{i}=1 .
$$

Анизотропия образца может быть связана как с анизотропией формы, так и с анизотропным распределением микрокристаллов. При случайной ориентации микрокристаллов анизотропия образца может быть связана только с зависимостью фактора заполнения от направления.

Из полученных данных мы можем оценить величину анизотропии фактора заполнения. Средняя толщина образца оценивается по количеству осажденного материала и составляет порядка $5 \mu \mathrm{m}$. Наличие оптической оси приводит к тому, что обыкновенный и необыкновенный лучи распространяются с разными фазовыми скоростями. Это проявляется в конверсии линейной поляризации в круговую. Если толщина образца такова, что разность фаз этих лучей кратна $2 \pi$, то конверсии поляризаций не происходит. Это и есть изотропная точка в спектре. Отсюда получаем, что разность эффективных показателей преломления $\sqrt{\varepsilon_{e f f}^{\|}}-\sqrt{\varepsilon_{e f f}^{\perp}} \approx 0.15$, и следовательно, анизотропия фактора заполнения $f^{\|}-f^{\perp}$ составляет всего 0.08. Такая маленькая величина не может быть ярко выраженной, но наблюдается в спектрах пропускания.

Мы считаем, что в нашем случае при расщеплении объемных кристаллов BN в ультразвуковой ванне полученные микрокристаллики электризуются в результате разрыва химических связей и затем, при осаждении, они слипаются упорядоченным образом в соответствии с направлением дипольного момента. В результате таких анизотропных корреляций в распределении микрокристаллов их плотность в разных направлениях может оказаться разной. На глаз это может быть и не заметно (см. рис. 1, $a$ в [13]), но в поляризации может проявиться. Действительно, при электризации диэлектрических кристаллов электростатические поля могут оказаться достаточными для их упорядочения.

\section{4. Заключение}

Путем расщепления объемных образцов в ультразвуковой ванне были изготовлены тонкие пленки гексагонального нитрида бора толщиной несколько моноатомных слоев. Исследовались спектры пропускания, отражения и фотолюминесценции таких пленок в области ниже края фундаментального поглощения. Измерены спектральные зависимости линейной и круговой поляризации прошедшего через образец света. Исследование с помощью сканирующей электронной микроскопии показало отсутствие заметных выделенных направлений в образце. Однако при исследовании параметров Стокса прошедшего через образец света обнаружилось явление двулучепреломления. Установлено, что оптические оси имеют одно и то же направление по всей площади образца. При этом рассеянный образцом свет был не поляризован. Это указывает на то, что причина анизотропии не заключается в свойствах отдельных микрокристаллов, а является общей для всего образца и связана с анизотропией фактора заполнения.

\section{Конфликт интересов}

У авторов нет конфликта интересов.

\section{Список литературы}

[1] P. Moon, M. Koshino. Phys. Rev. B 90, 155406 (2014).

[2] C. Ronning, A.D. Banks, B.L. McCarson, R. Schlesser, Z. Sitar, R.F. Davis, B.L. Ward, R.J. Nemanich. J. Appl. Phys. 84, 5046 (1998).

[3] B.T. Hogan, E. Kovalska, M.O. Zhukova, M. Yildirim, A. Baranov, M.F. Craciun, A. Baldycheva. Nanoscale 11, 16886 (2019).

[4] A. Akbari, P. Sheath, S.T. Martin, D.B. Shinde, M. Shaibani, P.C. Banerjee, R. Tkacz, D. Bhattacharyya, M. Majumder. Nature Commun. 7, 10891 (2016).

[5] K. Fu, Y. Wang, C. Yan, Y. Yao, Y. Chen, J. Dai, S. Lacey, Y. Wang, J. Wan, T. Li, Z. Wang, Y. Xu, L. Hu. Adv. Mater. 28, 2587 (2016).

[6] R. Jalili, S. Aminorroaya-Yamini, T.M. Benedetti, S.H. Aboutalebi, Y. Chao, G.G. Wallace, D.L. Officer. Nanoscale 8, 16862 (2016).

[7] P. Shaban, E. Oparin, M. Zhukova, B. Hogan, E. Kovalska, A. Baldycheva, A. Tsypkin. AIP Conf. Proc. 2300, 020111 (2020).

[8] B.T. Hogan, E. Kovalska, M.F. Craciun, A. Baldycheva. J. Mater. Chem. C 5, 11185 (2017).

[9] D.-W. Shin, M.D. Barnes, K. Walsh, D. Dimov, P. Tian, A.I.S. Neves, C.D. Wright, S.M. Yu, J.-B. Yoo, S. Russo, M.F. Craciun. Adv. Mater. 30, 1802953 (2018).

[10] M.O. Zhukova, B.T. Hogan, E.N. Oparin, P.S. Shaban, Y.V. Grachev, E. Kovalska, K.K. Walsh, M.F. Craciun, A. Baldycheva, A.N. Tcypkin. Nanoscale Res. Lett. 14, 225 (2019).

[11] С.Н. Гриняев, Ф.В. Конусов, В.В. Лопатин. 44, 2, 275 (2002).

[12] T.B. Ngwenya, A.M. Ukpong, N. Chetty. Phys. Rev. B 84, 245425 (2011).

[13] G. Jacucci, J. Bertolotti, S. Vignolini. Adv. Opt. Mater. 7, 1900980 (2019).

[14] A. Segure, L. Artus, R. Cusco, T. Taniguchi, G. Cassabois, B. Gil. Phys. Rev. Mater. 2, 024001 (2018).

[15] L.V. Kotova, A.V. Platonov, A.V. Poshakinsky, T.V. Shubina. Semiconductors 54, 1509 (2020).

[16] А.П. Виноградов. Электродинамика композитных материалов. / Под ред. Б.З. Каценеленбаума. Эдиториал УРСС, M. (2001). C. 208.

Редактор Е.Ю. Флегонтова 